\title{
Larval growth in polyphenic salamanders: making the best of a bad lot
}

\author{
H. H. Whiteman ${ }^{1,6} \bullet$ S. A. Wissinger ${ }^{2,6} \bullet$ M. Denoël ${ }^{3,6} \bullet$ C. J. Mecklin ${ }^{4}$ • N. M. Gerlanc ${ }^{1,6} \bullet$ J. J. Gutrich ${ }^{5,6}$

\begin{abstract}
${ }^{1}$ Department of Biological Sciences and Watershed Studies Institute, Murray State University, Murray, KY 42071, USA ; ${ }^{2}$ Biology and Environmental Science Departments, Allegheny College, Meadville, PA 16335, USA; ${ }^{3}$ Laboratory of Fish and Amphibian of Mathematics and Statistics and Watershed Studies Institute, Murray State University, Murray, KY 42071, USA; ${ }^{5}$ Department of Environmental Studies, Southern Oregon University, Ashland, OR 97520, USA; ${ }^{\circ}$ Rocky Mountain Biological Laboratory,
\end{abstract} \\ Ethology, Behavioural Biology Unit, Department of Environmental Sciences, University of Liège, 4020 Liège, Belgium; ${ }^{4}$ Department \\ P. O. Box 519, Crested Butte, CO 81224, USA
}

\begin{abstract}
Polyphenisms are excellent models for studying phenotypic variation, yet few studies have focused on natural populations. Facultative paedomorphosis is a polyphenism in which salamanders either metamorphose or retain their larval morphology and eventually become paedomorphic. Paedomorphosis can result from selection for capitalizing on favorable aquatic habitats (paedomorph advantage), but could also be a default strategy under poor aquatic conditions (best of a bad lot). We tested these alternatives by quantifying how the developmental environment influences the ontogeny of wild Arizona tiger salamanders (Ambystoma tigrinum nebulosum). Most paedomorphs in our study population arose from slow-growing larvae that developed under high density and size-structured conditions (best of a bad lot), although a few faster-growing larvae also became paedomorphic (paedomorph advantage). Males were more likely to become paedomorphs than females and did so under a greater range of body sizes than females, signifying a critical role for gender in this polyphenism. Our results emphasize that the same phenotype can be adaptive under different environmental and genetic contexts and that studies of phenotypic variation should consider multiple mechanisms of morph production.
\end{abstract}

Keywords: Polyphenism - Density dependence - Size structure - Facultative paedomorphosis - Ambystoma tigrinum

\section{Introduction}

Understanding the maintenance of phenotypic variation is one of the most fundamental questions in evolutionary ecology (Schlichting and Pigliucci 1998; West-Eberhard 2003; Nussey et al. 2007; Pfennig et al. 2010). Environmentally-cued polymorphisms (polyphenisms), which occur when discretely different phenotypes develop from genotype by environment interactions, provide excellent opportunities for understanding the mechanisms producing and maintaining phenotypic variation and plasticity (West-Eberhard 1986, 2003; Hazel et al. 1990, 2004; Scheiner 1993; Roff 1996; Relyea 2002; Tomkins and Hazel 2007). Polyphenisms provide model systems for the study of phenotypic variation because: (1) the trait of interest has a direct environmental component; (2) alternative phenotypes are often distinct and easily distinguished; and (3) they are likely to be a direct result of selection (Caswell 1983; Smith-Gill 1983). Documenting the ecological and evolutionary contexts that produce and maintain polyphenisms is critical for understanding their role in speciation, life history evolution, the maintenance of biodiversity, and the evolution of plasticity (West-Eberhard 1986, 1989, 2003, 2005; Hazel et al. 1990; Via 2001; Denoël et al. 2005; Emlen et al. 2007; Pfennig et al. 2007, 2010; Tomkins and Hazel 2007; Pfennig and McGee 2010).
Facultative paedomorphosis is a polyphenism that is expressed in some salamanders such that individuals either transform into terrestrial metamorphic adults or remain in the aquatic environment to mature as paedomorphic adults, depending on the environmental conditions experienced during larval development (Fig. 1; Whiteman 1994; Denoël et al. 2005). The expression of each morph is considered to be a response to the individual's expected success in the aquatic versus terrestrial environment (Wilbur and Collins 1973). Facultative paedomorphosis is characterized as an environmental threshold trait, i.e., there is genetic variation with an environmental trigger (Harris 1987; Harris et al. 1990; Roff 1996), and there is considerable support for the hypothesis that the origin and maintenance of facultative paedomorphosis is a result of selection (reviewed in Whiteman 1994; Denoël et al. 2005).

Two major mechanisms have been proposed for explaining how environmental conditions can select for the production and maintenance of facultative paedomorphosis in salamanders (Whiteman 1994; Table 1). The "paedomorph advantage" mechanism assumes that paedomorphosis is selected when growing conditions are better in the aquatic environment (e.g., lower conspecific densities, higher food levels, optimal temperatures, and/or lower risk of predation) than in the terrestrial environment. Thus large larvae and and/or those in good condi-

The present pdf is the author postprint (i.e., post-refereed version of the manuscript). The paginated published pdf is available in an institutional repository (http://hdl.handle.net/2268/97214) and in the publisher website (http://dx.doi. org/10.1007/s00442-011-2076-z) (Springer). 
tion become paedomorphs to take advantage of the beneficial growth conditions in the aquatic environment, whereas small larvae and those in poor condition metamorphose to escape competition and cannibalism from large larvae and paedomorphic adults. Under this scenario, paedomorphosis is predicted to be negatively density-dependent, with the frequency of larvae becoming paedomorphic decreasing as salamander density increases. Both competitive and predatory interactions will vary with size structure (Werner and Gilliam 1984; Wissinger 1989; Van Buskirk and Smith 1991; Persson et al. $2000,2004)$ and thus could subsequently impact the expression of paedomorphosis. The paedomorph advantage hypothesis predicts that paedomorphosis will be negatively related to population size structure, as estimated by size variation; as size variation increases, a greater proportion of larvae should metamorphose to escape competition with larger individuals. Numerous field and experimental studies support the idea that the development of paedomorphs is an adaptive response to good growth/survival conditions in the aquatic environment (Whiteman 1994; Denoël et al. 2005).

Alternatively, the "best of a bad lot" mechanism asserts that paedomorphosis arises as a default strategy when the growing conditions are so poor that larvae cannot reach the minimum critical size for metamorphosis (Wilbur and Collins 1973; Wilbur 1980). Those larvae that reach this critical size metamorphose into terrestrial adults, but for slowgrowing larvae, the fitness benefits of becoming reproductive as paedomorphic adults outweigh those of remaining in the larval stage, or attempting metamorphosis at a small size. Thus, larger individuals and/or those in good condition metamorphose, while smaller larvae or those in poor condition become paedomorphic (Table 1). Best of a bad lot paedomorphosis is predicted to be positively density-dependent, with the frequency of paedomorphosis increasing as salamander density increases, and positively related to population size structure, as more larvae are forced into paedomorphosis because of competition with larger individuals. Fewer empirical data are consistent with this mechanism as compared to the paedomorphic advantage (Whiteman 1994; Denoël et al. 2005, 2007; Doyle and Whiteman 2008).

Both hypotheses suggest that relative body size (i.e., the body size of a larvae relative to other

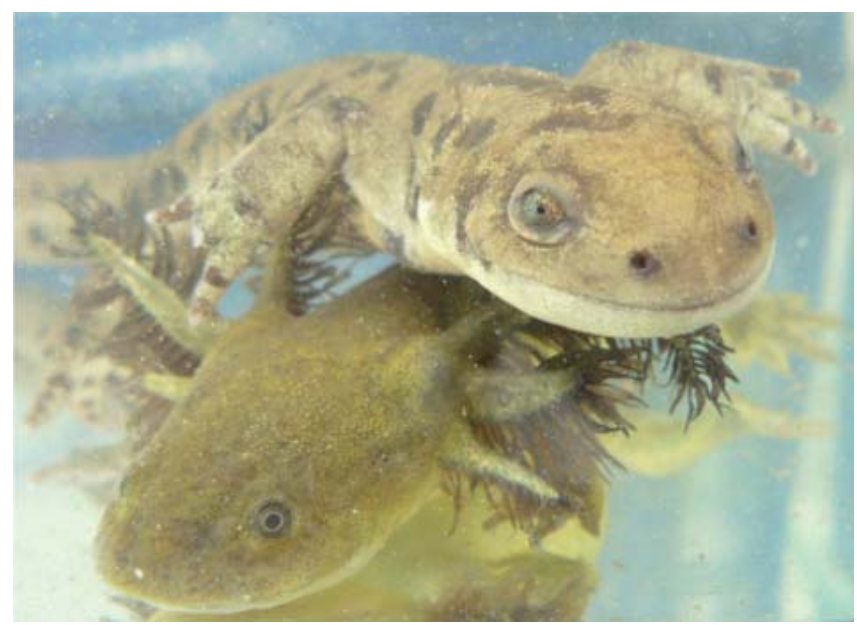

Fig. 1. Metamorphic (top) and paedomorphic (bottom) Arizona tiger salamanders (Ambystoma tigrinum nebulosum) from the Mexican Cut Nature Preserve. Note the larval morphology (e.g., external gills) in the paedomorph members of the larval population) can influence the "decision" of individual larvae to metamorphose or become paedomorphic (Whiteman 1994), and salamander larvae can assess their relative body size through direct competitive or predatory interactions with conspecifics (e.g., Brunkow and Collins 1996, 1998; Maret and Collins 1997; Johnson et al. 2003; Whiteman et al. 2003). Alternatively, such decisions might not be based on relative size alone, but rather on both size and body condition. Salamanders have physiological mechanisms that allow them to assess and maintain homeostasis (Feder and Burggren 1992; Kikuyama et al. 2005; Stiffler 2005). Such mechanisms provide an intrinsic monitor for body condition (e.g., gut fullness and blood lipid titers in the short term, and fat storage in the long term), and indirectly allow an assessment of environmental quality (Denoël et al. 2002), similar to that described in insects (e.g., Emlen et al. 2007).

Here, we test the two major hypotheses of paedomorph production (paedomorphic advantage, best of bad lot) using data on the relationship between larval growth and paedomorphosis in a subalpine population of the tiger salamander, Ambystoma tigrinum nebulosum (Hallowell). This population is ideal for this research because larval growth is protracted as a result of cold temperatures and short growing seasons (Sexton and Bizer 1978; Wissinger et al. 1999). Thus, the population contains multiple size/age classes of larvae whose development can be followed longitudinally under different densities and competitive/predatory selection pressures. By comparing the ontogenetic trajectories of larvae from different cohorts and different ponds, we determined: (1) how body size affects whether larvae metamorphose or become paedomorphic; and (2) how environmental variables affect larval growth and morph production. Few researchers have attempted to correlate the environmental variables that influence larval growth with the production of paedomorphs in natural systems, and those that have did so using short-term studies (Bizer 1978; Semlitsch 1985). In our study, we followed the ontogenetic trajectories of individuals in natural habitats to quantify how differences in larval growth affect adult fate and thus paedomorph production.

\section{Materials and methods}

Study organism and study site

Tiger salamanders (Ambystoma tigrinum) are found throughout North America, and the western

Table 1. Predictions of the two major hypotheses for facultative paedomorphosis

\begin{tabular}{lcccc}
\hline & \multicolumn{3}{l}{ Relationship between: } \\
\cline { 2 - 5 } & $\begin{array}{l}\text { Larvae becoming } \\
\text { each morph }\end{array}$ & $\begin{array}{l}\text { Variable and \% of } \\
\text { larvae becoming } \\
\text { paedomorphic }\end{array}$ \\
\hline Variable & PA & BBL & PA & BBL \\
Body size & P $>$ M & $\mathbf{M}>\mathbf{P}$ & + & - \\
Body condition & P $>$ M & $\mathbf{M}>\mathbf{P}$ & + & - \\
Conspecific density & & - & - & + \\
Size structure & -- & - & - & + \\
\hline
\end{tabular}

Predictions in bold are those that were supported by this study PA paedomorph advantage, BBL best of a bad lot, $\mathrm{P}$ larvae that became paedomorphic, M larvae that metamorphosed 
subspecies, A. t. nebulosum, is often facultatively paedomorphic (Fig. 1; Behler and King 1979; Collins 1981). A. t. nebulosum occurs in a variety of aquatic habitats from western Colorado and Utah to south-central New Mexico and central Arizona (Behler and King 1979). The population studied here is within the Mexican Cut Nature Preserve, a Nature Conservancy property located in western Colorado $\left(3,640 \mathrm{~m}\right.$ asl; $\left.39.02^{\circ} \mathrm{N}, 107.06^{\circ} \mathrm{W}\right)$. The Mexican Cut ponds vary dramatically in hydroperiod and other environmental variables (Wissinger and Whiteman 1992; Wissinger et al. 1999; Whiteman and Wissinger 2005). Here, we focus on five of the largest ponds that are permanent $(1,3,5,9$, and 12 ), thus providing suitable habitat for paedomorphosis.

Larval growth at this study site is protracted because of short growing seasons and cold alpine temperatures; thus, several age classes of larvae as well as paedomorphic adults occur in the permanent ponds (Sexton and Bizer 1978; Wissinger et al. 1999). Some individuals metamorphose after two summers, but most do not reach the minimum size for metamorphosis (approximately $62 \mathrm{~mm} \mathrm{SVL}$; $\mathrm{H}$. Whiteman, unpublished data) until their third summer of larval growth (as was true for all the larvae in this study). Larvae that do not metamorphose after their third summer eventually become paedomorphic, although sexual maturity often requires several additional years. After becoming paedomorphic, only a few individuals $(<3 \%)$ successfully metamorphose later in life (H. Whiteman, unpublished data). Growth and abundance of larval cohorts vary considerably across years and ponds, depending on the number of eggs laid in each pond and environmental effects such as pond drying and cannibalism (Wissinger and Whiteman 1992; Whiteman and Wissinger 2005; Wissinger et al. 2010).

Salamander cohorts at Mexican Cut were monitored during the summers of 1988-2002. We present data for the fate (maturation as a metamorphic or paedomorphic adult) of individuals from the following pond-cohorts for which there were sufficient data for statistical analysis: the 1988 cohort in ponds $1,3,5,9$ and 12 ; the 1990 cohort in ponds 1 and 12; and the 1991 cohort in pond 9. Low recruitment and/or survival to the second year precluded analysis for other pond-cohorts (Whiteman and Wissinger 2005; Wissinger et al. 2010).

Salamanders were captured by hand or with dip nets, and identified visually to age class/morph and sex. Larval age classes were determined by size and developmental differences (e.g., limbs, toes, and gills) among the classes. Paedomorphic adults have larval characteristics such as a flattened, U-shaped head, gills, and broad tail fin while showing evidence of sexual maturity, while metamorphs have rounded heads and lacked gills and a tail fin. Sex was determined by visual inspection of the cloaca: males have a large slit-like vent with enlarged black papillae, females have a rounded, slightly swollen vent, and immatures have a small, slit-like vent which lack papillae or distinctive shape. We measured mass and snout-vent length (SVL; distance from the snout to the posterior end of the cloaca), marked individuals with unique toe clips, and scored individuals for general condition. Because the ponds are extremely isolated, individuals that were not recaptured during this study were presumed dead or to have remained in the surrounding terrestrial environment (Whiteman et al. 1995; Whiteman and Wissinger 2005).
Larval growth, environmental variation, and paedomorphosis

We compared patterns of larval growth within and between cohorts using both absolute body size (SVL) and an estimate of body condition (expressed as mass/SVL). For all within-cohort body size and condition comparisons across ponds, data were collected at similar times so that between-pond body size differences could not be caused by differences in the timing of measurements, as all larvae were of similar age. Additionally, all measurements were made in the month prior to the first metamorphosis event for each cohort (early August). We compared the effects of body size or condition and the eventual sex of individuals on the fate of larvae (metamorphosed versus paedomorphic) using Generalized Linear Mixed Models (GLMM; fit with the Laplace approximation; Bolker et al. 2009), with pond of origin as a random effect. We also compared the coefficient of variation (C.V.) of body condition using a likelihood ratio test and frequency distributions by inspection to evaluate variation in individual responses of larvae. Here and below, all assumptions of statistical tests were either met before analysis or data were transformed appropriately.

We estimated the percentage of larvae that became paedomorphic in a pond-cohort by dividing the number of paedomorphic adults produced within the cohort by the total number of larvae with known fate (metamorphic or paedomorphic) and multiplying by 100 . To test how growth conditions influenced this percentage, we compared this result to the mean body size and condition of larvae within a pond-cohort using regression analysis.

We also compared the percentage of larvae that became paedomorphic to estimates of conspecific density, size structure, and benthic invertebrate resource levels. To calculate conspecific density, the number of larvae in each pond-cohort prior to metamorphosis was estimated using the LincolnPeterson method (Pollock et al. 1990). Larval densities were calculated by dividing each estimate by the previously determined surface area of each pond (Wissinger and Whiteman 1992). Density estimates were generated within a cohort, which made up the majority of the total salamander density within the ponds, as well as among larger and/or smaller, non-cohort larvae (i.e., slightly older cohorts that were not paedomorphic as well as younger cohorts). Paedomorphic adults were the primary predators of larvae in permanent ponds (Whiteman and Wissinger 2005; Wissinger et al. 2010); thus, we used paedomorphic adult densities as estimates of predation pressure. Metamorphic adult densities were not included because they were very low across permanent ponds and because metamorphs feed on different prey (Whiteman et al. 1995, 1996; Wissinger et al. 1999; Denoël et al. 2007). We estimated size structure using the C.V. of SVL among gilled salamanders within each pond during the month prior to metamorphosis.

Benthic prey densities were estimated for each pond from four $0.125-\mathrm{m}^{2}$ samples taken with a drop box and D-shaped aquatic net in June and July 1989-1992 (Wissinger et al. 1999). Prey densities were averaged between the 2 nd and 3 rd summer of larval development for each pond-cohort of salamanders.

Preliminary analyses revealed that the singular effects of cohort density, large non-cohort density, paedomorph density, and benthic prey densities were not adequately variable across pond-cohorts for further analyses. However, we summed the first 
three variables to provide an estimate of total gilled salamander density for each pond-cohort. The effects of total gilled salamander density and sizestructure on body size, body condition and the percentage of salamanders becoming paedomorphic were analyzed using multiple regression.

\section{Results}

\section{Larval growth and fate}

Larvae from the 1988 cohort that metamorphosed into terrestrial adults were significantly larger and in better body condition than those that became paedomorphic, and those becoming paedomorphic were significantly larger and in better condition than those individuals whose last known fate was as an immature larva (Fig. 2a, b; SVL: Wald's $z=$ 3.62, $P<0.001$; condition: $z=3.52, P<0.001)$. Sex also affected the production of paedomorphs within both analyses (both $z<-2.46$, both $P<0.015$ ), with males more likely to become paedomorphic, but neither the SVL $\times$ sex nor the condition $\times$ sex interaction was significant (both $z>-1.31$, both $P$ $>0.19)$. Removing immature larvae from these analyses did not change the results between morphs. Larvae from the 1990 cohort exhibited similar results (SVL: $z=2.09, P=0.037$; condition: $z=2.14$, $\mathrm{P}<0.033$ ), although neither the sex main effects nor the interactions were significant (all $\mathrm{P}>0.14)$.

The coefficient of variation (CV) for condition within cohorts was marginally greater for 1988 larvae becoming paedomorphic $(0.149)$ versus metamorphic $(0.105)$ in pond 1 (likelihood ratio test, $P$ $=0.07$ ), but did not differ in ponds 5 or 12 (both $P$ $>0.33)$. Individuals that became paedomorphic in ponds 1 and 5 typically had low condition values compared to those that metamorphosed, but those in pond 12 became paedomorphic at both high and low body condition values (Fig. 3). In pond 1, where there were sufficient data to compare sexes, the population of larvae that became paedomorphic males had a CV $(0.173)$ that was more than three times that of the population that became metamorphic males (0.048), and more than twice that of the populations becoming paedomorphic (0.091) or metamorphic females (0.079) (Fig. 4; all $P<0.03$ ). The population of larvae that became paedomorphic females had a marginally greater $C V$ than the group becoming metamorphic males $(P=0.06)$, but the other morph-sex comparisons were not significantly different (all $P>0.21$ ). Larvae that became paedomorphic males tended to have lower and higher body condition than all of the other morph-sex combinations (Fig. 4).

The CV of body condition of 1990 cohort larvae in pond 12 that became paedomorphic was marginally greater than those that metamorphosed $(P=$ $0.06)$, and paedomorphs were more frequent at both higher and lower condition values (Fig. 3 ). No other pond had sufficient numbers of larvae from this cohort to compare CV distributions.

The sex ratios of larvae that became metamorphs vs. paedomorphs in the 1988 cohort varied significantly $(\chi 2=3.9, P<0.05, \mathrm{df}=1$; other cohorts were too small for analysis). Across all ponds, larvae that became paedomorphic were significantly male biased ( 89 males vs. 56 females; $\chi 2=7.5, P<$ 0.01 , df $=1)$, whereas larvae that metamorphosed did not vary in sex ratio ( 31 males vs. 35 females; $\chi 2=0.24, P>0.05, \mathrm{df}=1)$. Metamorph sex ratios did not vary among ponds, but paedomorph ratios did, with those from ponds 1 and 12 contributing
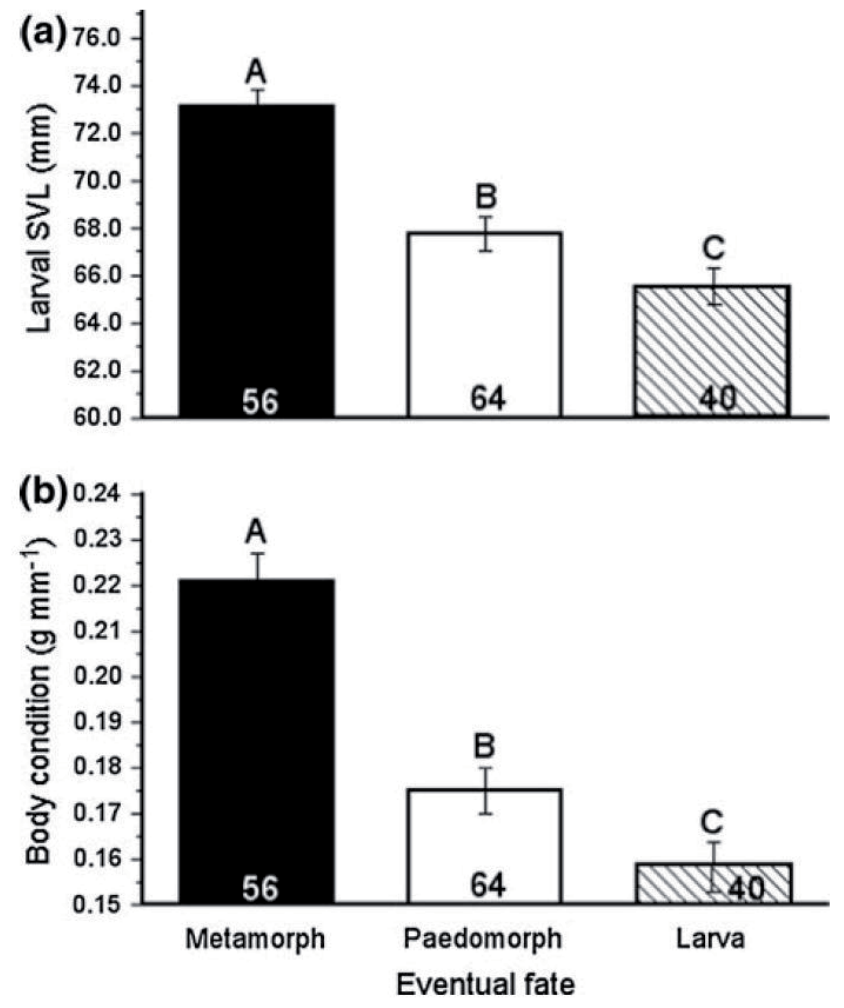

Fig. 2. a Snout-vent length (SVL) and b body condition (mass/SVL) of Arizona tiger salamander (Ambystoma tigrinum nebulosum) larvae that either eventually metamorphosed (black bars), became paedomorphic (white bars) or remained larval (hatched bars), mean \pm SE. Different letters indicate significantly different groups; sample sizes are shown with each bar. Wald's $\mathrm{z}$, both $\mathrm{P}<0.001$

most to the overall male bias (pond 1: $53 \mathrm{M}: 33 \mathrm{~F} ; 12$ : 12:2; both $P<0.05$, others NS).

\section{Environmental factors}

The percentage of larvae in a pond-cohort that became paedomorphic was negatively related to mean body size (SVL: $\left.F_{1,6}=8.9, P=0.02, R^{2}=0.60\right)$ and condition (mass/SVL: Fig. $5 \mathrm{a} ; F_{1,6}=22.7, P=0.003$, $\left.R^{2}=0.79\right)$. Multiple regression revealed that among the environmental variables, size structure was strongly and positively related to this percentage (CV of SVL among gilled salamanders: Fig. $5 \mathrm{~b} ; F_{2,5}$ $=15.4, P=0.007, R^{2}=0.86$, partial correlation (pr) $=0.82$ ). The total density of gilled salamanders was not a significant predictor of percent paedomorphosis after taking size structure into account, although the two variables were positively related $(\mathrm{pr}=0.45)$. Mean body size and condition were negatively related to total gilled salamander density and size structure. Total gilled salamander density had a stronger effect on mean body size than size structure (SVL: $F_{2,5}=7.6, P=0.03, R^{2}=0.75$, pr: density $=-0.66$, $\mathrm{CV}=-0.44)$, but both variables were similarly related to body condition $\left(F_{2,5}=22.9, P=0.003, R^{2}=\right.$ 0.90 , pr: density $=-0.77, \mathrm{CV}=-0.76$; Fig. $5 \mathrm{c})$. Size structure was marginally, but positively, related to total gilled salamander density $\left(F_{1,6}=5.5, P=0.058\right.$, $R^{2}=0.48$ ). 


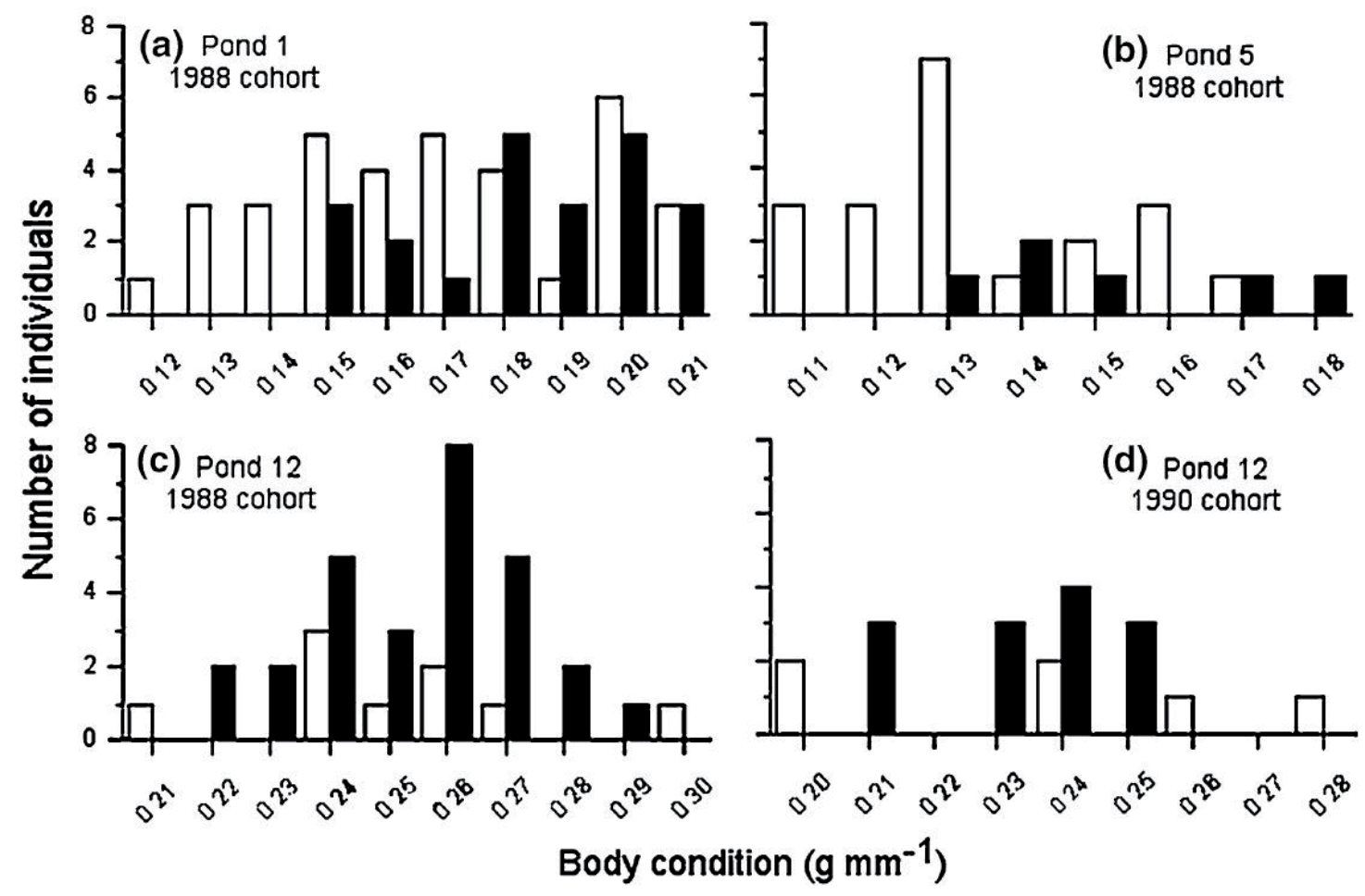

Fig. 3. Body condition distributions for larvae that eventually metamorphosed (black bars) or became paedomorphic (white bars) for the 1988 cohort in a Pond 1, b Pond 5, c Pond 12 and d 1990 cohort in Pond 12

\section{Discussion}

\section{Conditions that favor paedomorphosis}

Facultative paedomorphosis has been traditionally thought of as a result of selection for taking advantage of favorable aquatic habitats, such that salamander larvae extend the time they can benefit from abundant resources or advantageous growth conditions, and at the same time become reproductive (Wilbur and Collins 1973). Alternatively, paedomorphosis can be adaptive as a best of a bad lot strategy (Whiteman 1994). The data presented here document that most paedomorphs at our study site were produced through a best of a bad lot mechanism (Table 1). Most larvae that became paedomorphic adults were significantly smaller and in poorer body condition than those that metamorphosed into terrestrial adults (Fig. 2). Across all pond-cohorts, the percentage of larvae becoming paedomorphic was negatively related to body size and condition (Fig. 5a), and positively related to size structure (Fig. 5b); both size structure and total gilled salamander density were negatively related to both body measures (Fig. 5c). All of these relationships support a best of a bad lot interpretation.

There are several mechanisms that could underlie the observed size- and density-dependent relationships, most notably competition within large cohorts and threat of cannibalism by older paedomorphs. Similarly sized ambystomatid larvae have high dietary and microhabitat overlap (Smith 1990; Johnson et al. 2003), and invertebrate prey biomass in the ponds at our study site declines dramatically as large salamander cohorts mature (S.A. Wissinger, unpublished data). Thus, the cohorts (e.g., 1990, 1991) that trail large cohorts (e.g., 1988) develop in the context of high densities of similarly sized conspecifics and depressed resources (both conditions favoring competition). Experimental data also

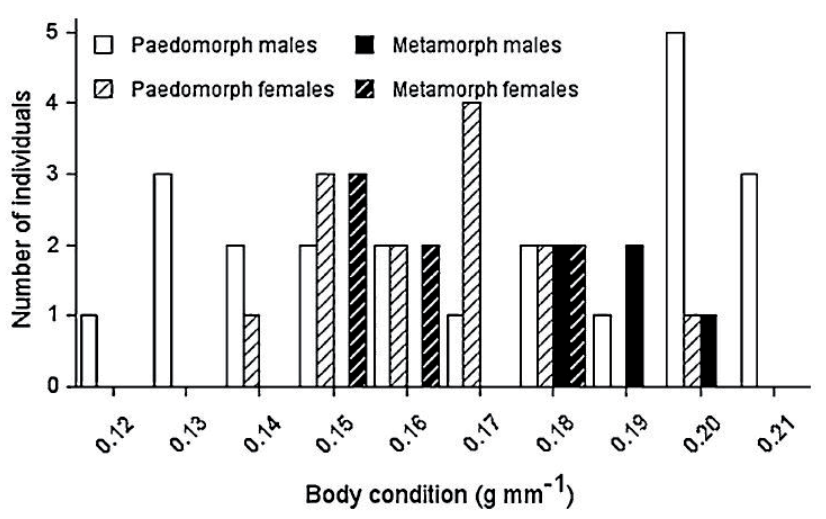

Fig. 4. Body condition distributions for larvae from the 1988 cohort in pond 1 , separated by morph and sex. Paedomorphic males white, paedomorphic females white hatched, metamorphic males black, metamorphic females black hatched. Some metamorphs in Fig. 3a were immature at capture, which reduced the sample size of metamorphs in this figure

indicate that individuals in those trailing cohorts are vulnerable to the lethal and non-lethal effects associated with cannibalism by large larvae and paedomorphs (Wissinger et al. 2010). Non-lethal effects of the threat of cannibalism such as reduced activity levels and reduced foraging contribute to reduced growth rates of small larvae, reinforcing the poor growth conditions that lead to best of a bad lot paedomorphosis. In large cohorts that develop during years with few large larvae or paedomorphs, within-cohort competition among similarly-sized larvae is the most likely mechanism that underlies slow growth, hence paedomorphosis, whereas in cohorts that mature in the presence of large larvae or paedomorphs, between-cohort competition and canniba- 

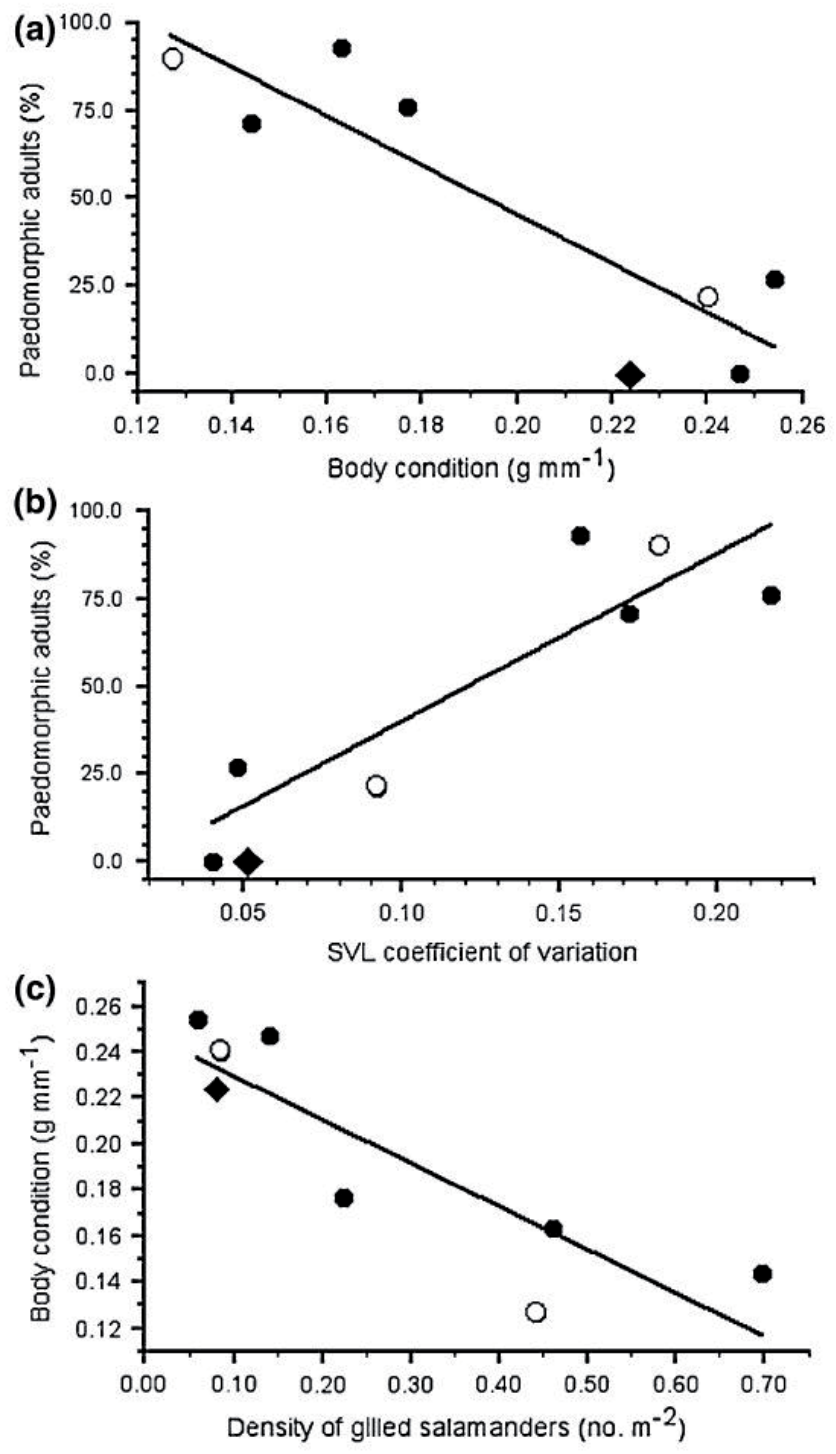

Fig. 5. Percentage of paedomorphic adults produced in a pond-cohort as a function of a mean body condition (mass/SVL) and b the coefficient of variation (CV) in total salamander SVL within a pond (hence, degree of size structure). c Body condition as a function of the total density of gilled salamanders in a pond. Data of 3 cohorts shown: 1988 (filled circles), 1990 (open circles), 1991 (filled diamonds). Best-fit regression lines incorporate all data; see text for statistics

lism are likely to play a larger role (Wissinger et al. 2010). Thus, there is a strong positive relationship between size structure and paedomorphosis (Fig. $5 \mathrm{~b})$. Although we have evidence that all of these mechanisms (within-cohort competition, betweencohort competition, cannibalism, resource depression; Wissinger et al. 2010; Wissinger et al., unpublished manuscript; this paper) can contribute to negative density-dependent growth via variation in size structure, understanding their relative importance will require experimental manipulation.

In three different pond-cohorts, extremely small and extremely large larvae became paedomorphs (Fig. 3), providing evidence that paedomorphs can arise from both the paedomorph advantage and best of a bad lot mechanism (the 'dimorphic paedomorph' hypothesis in Whiteman (1994)). The dimorphic paedomorph hypothesis was originally proposed to account for temporal fluctuations in pond conditions that could lead to alternating cohorts that favor either mechanism within a single population, or size-structure in a single cohort that produces paedomorphs through both mechanisms (Whiteman 1994; Wakano and Whiteman 2008). To the best of our knowledge, this is the first evidence for paedomorphs being produced through both mechanisms in natural populations, and is similar to that observed in experimental manipulations (Doyle and Whiteman 2008). Our ability to detect the subtle evidence for the presence of both mechanisms operating simultaneously in this population depended on following individuals within and between cohorts and evaluating how the relative sizes of larvae within a cohort were related to their eventual fates (Doyle and Whiteman 2008).

Larval males from the 1988 cohort were more likely to become paedomorphs than females, and became paedomorphic under a wider range of body conditions than females (Fig. 3). Paedomorphic adults produced from the 1988 cohort were significantly male biased ( $89 \mathrm{M}: 56 \mathrm{~F})$, whereas the sex ratio in metamorphic adults was not statistically different from 1:1 (31M:35F). Sex-ratios of paedomorphs in pond 12 were strongly skewed toward males (12M:2F), perhaps because of an apparent trade-off between mortality and large body size: gilled salamanders in pond 12 exhibit low yearly survival due to winter kill (Whiteman, unpublished data), but have extremely high growth rates and body condition relative to other ponds (Figs. 3 and 4 ). This result suggests that larval males, due to their higher variance in reproductive success (Trivers 1972), are most likely to attempt a risky strategy (e.g., paedomorphosis in a pond with high mortality; see also Church et al. 2007). The frequency distribution of body conditions in pond 1 (Fig. 3 ) suggests that larval males are more likely to become paedomorphic at lower body condition values than females, which is also consistent with a risk-sensitive hypothesis. These results correspond to previous data from this population, which showed that sex-specific fitness payoffs underlie similar sex-ratio biases (Whiteman 1997; Whiteman et al., unpublished data), and support the hypothesis that the production and maintenance of paedomorphosis is due, at least in part, to sex differences (Whiteman 1997; Winne and Ryan 2001). Because few studies have considered the effects of sex in similar polyphenisms (see Roff and Fairbairn 1993; Roff et al. 2002, 2003 for notable exceptions), this variable should be considered more carefully in future theoretical and empirical investigations (West-Eberhard 2005).

Facultative paedomorphosis and the evolution of phenotypic variation

The maintenance of phenotypic plasticity has been largely attributed to spatially and/or temporally heterogeneous environments (e.g., reviews by Schlichting 1986; West-Eberhard 1989, 2003; Thompson 1991; Stearns 1992; Scheiner 1993; Via et al. 1995; Roff 1996; Schlichting and Pigliucci 1998; DeWitt et al. 1998). In the case of facultative paedomorphosis, environmental heterogeneity includes both between-year variation within a single pond and within-year variation across ponds. Our data suggest that alternative selection mechanisms (paedomorph advantage vs. best of a bad lot) are operating across these spatiotemporal gradients because different cohorts within and between ponds varied in their morphogenesis patterns (Fig. 3).

Multiple selection mechanisms might operate most readily in systems that are most susceptible to influence from spatiotemporal variation. For example, facultative paedomorphosis, wing dimor- 
phisms (Roff 1986; Aukema 1995), and other dispersal polyphenisms (McPeek and Holt 1992) may exhibit multiple mechanisms both within and between populations because the benefit to cost ratio of living in one habitat versus another can change over short time spans and between different populations. Some trophic polyphenisms may also be a product of multiple selection mechanisms. For example, in polyphenic tadpoles, carnivore versus omnivore morphs can be produced in response to several environmental variables (Pfennig 1992. Frankino and Pfennig 2001; Pfennig et al. 2007), and different populations and species exposed to different environments reveal substantial variation in the production of the two morphs (Pfennig et al. 2007), suggesting multiple mechanisms for morph production and maintenance. In contrast, environments with low spatiotemporal variation or in polymorphisms that are less affected by such variation, one selection mechanism may attain primacy, as is suggested by numerous studies showing 'primary' versus 'secondary' morphs, such as in alternative male morphologies (e.g., Gross 1996; Emlen et al. $2005,2007)$. In this sense, polyphenisms can be separated into those that are more extrinsically-driven by spatiotemporal variation (e.g., dispersal and trophic polyphenisms; see also Roff 1994) and those that are more intrinsically-driven by strong genotypic effects (e.g., alternative male morphologies).

Analysis of lifetime reproduction success is necessary to better understand the costs and benefits of such alternative selection mechanisms. As part of this long-term research, we are collecting fitness data that corroborate these results in part (Whiteman et al. 1996, Whiteman 1997), but also suggest that the evolutionary maintenance of this polyphenism may be more complex than the ecological mechanisms that produce the alternative morphs (Whiteman 1997; Whiteman et al., unpublished data; see also Whiteman and Semlitsch 2005; Whiteman et al. 2006).

Our results emphasize that a strong test of hypotheses about the evolutionary ecology of phenotypic variation should start with the assumption that multiple mechanisms could be involved, and that the mechanisms producing such variation may not be the same as those maintaining it. Long-term demographic studies of marked individuals, although challenging, may be the most accurate way to ascertain the factors involved in the production and maintenance of phenotypic variation.

\section{Acknowledgments}

This long-term research could not have been completed without the support and assistance of numerous colleagues, research assistants, funding agencies, and friends. We particularly thank R.D. Howard for his unending and much needed advice, wisdom, revisions, and patience during the initial phases of this project. W. Brown, A. Benson, J. Boynton, E. Olson, J. Doyle, J. Earl, A. Bohonak, S. Horn, G. McCrabb, R. Moorman, J. Marcus, J. McGrady-Steed, K. Buhn, D. Weigel, G. Maruca, M. Hatfield, C. Eden, H. Grieg, R. Schultheis, S. Mattie, D. Dale, M. Mumford, C. Aubee, E. Bruneau, M. Galatowitsch, M. O'Brien, and S. Thomason provided field and intellectual assistance. P. Waser, J. Lucas, N. Buschhaus, J. Young, M. Brown, A. Bohonak, J. Haydock, J. Doyle, K. Landholt, and J. Earl reviewed previous versions of the manuscript. J. Hetfield, L. Ulrich, K. Hammett, R. Trujillo, J. Newstead, and C. Burton provided intense encouragement. I. Billick,
B. Barr, S. Donovan, S. Lohr, T. Allison and L. Swift have provided much needed aid and assistance at the RMBL, and W. Gibbons, R. Semlitsch, D. White, G. Kipphut, and R. Fister patiently supported this work. M. Denoël was a Research Associate at the Fonds de la Recherche Scientifique (FRS-FNRS) during this research. This research was funded by a Purdue David Ross Summer Fellowship, a Purdue Research Foundation Fellowship, the American Museum of Natural History (Theodore Roosevelt Fund), Sigma Xi (Grant in Aid), the Rocky Mountain Biological Laboratory (Lee R. G. Snyder Memorial Fund), the American Society of Ichthyologists and Herpetologists (Helen Gaige Fund), the Animal Behavior Society (ABS Research Grant), the Colorado Division of Wildlife, the American Philosophical Society, the Murray State University Center for Institutional Studies and Research (CISR), a CISR Presidential Research Fellowship, a Fulbright Fellowship (MD), the Fonds National de la Recherche Scientifique (FRS-FNRS grants 1.5.011.03, 1.5.120.04, F.4718.06, 1.5.199.07, 1.5.013.08, and 1.5.010.09) and the $\mathrm{Na}$ tional Science Foundation (DEB 9122981 and DEB 0109436 to HW; BSR 8958253, DEB 9407856, and DEB 010893 to SAW; EPI 0132295 to G. Kipphut; and UBM 0531865 to R. Fister).

\section{References}

Aukema B (1995) The adaptive signficance of wing dimorphism in carabid beetles. Res Popul Ecol 37:105-110

Behler JL, King FW (1979) The Audubon Society field guide to North American reptiles and amphibians. Knopf, New York

Bizer JR (1978) Growth rates and size at metamorphosis of high elevation populations of Ambystoma tigrinum. Oecologia 34:175184

Brunkow PE, Collins JP (1996) Effects of individual variation in size on growth and development of larval salamanders. Ecology 77:1483-1492

Brunkow PE, Collins JP (1998) Group size structure affects patterns of aggression in larval salamanders. Behav Ecol 9:508-514

Bolker BM, Brooks ME, Clark CJ, Geange SW, Poulsen JR, Stevens MHH, White J-SS (2009) Generalized linear mixed models: a practical guide for ecology and evolution. Trends Ecol Evol $24: 127-135$

Caswell H (1983) Phenotypic plasticity in life-history traits: demographic effects and evolutionary consequences. Am Zool 23:3546

Church DR, Bailey LL, Wilbur HM, Kendall WL, Hines JE (2007) Iteroparity in the variable environment of the salamander $\mathrm{Am}$ bystoma tigrinum. Ecology 88:891-903

Collins JP (1981) Distribution, habitats, and life history variation in the tiger salamander, Ambystoma tigrinum, in east-central and southeast Arizona. Copeia 1981:666-675

Denoël M, Hervant F, Schabetsberger R, Joly P (2002) Short- and long- term advantages of an alternative ontogenetic pathway. Biol J Linn Soc 77:105-112

Denoël M, Joly P, Whiteman HH (2005) Evolutionary ecology of facultative paedomorphosis in newts and salamanders. Biol Rev 80:663-671

Denoël M, Whiteman HH, Wissinger SA (2007) Foraging tactics in alternative heterochronic salamander morphs: trophic quality of ponds matters more than water permanency. Freshw Biol 52:1667-1676

DeWitt TJ, Sih A, Wilson DS (1998) Costs and limits of phenotypic plasticity. Trends Ecol Evol 13:77-81

Doyle JM, Whiteman HH (2008) Paedomorphosis in Ambystomatalpoideum: effects of initial size variation and density. Oecologia 156:87-94

Emlen DJ, Hunt J, Simmons LW (2005) Evolution of sexual dimorphism and male dimorphism in the expression of beetle horns: phylogenetic evidence for modularity, evolutionary lability, and constraint. Am Nat 166:S42-S68 
Emlen DJ, Corley Lavine L, Ewen-Campen B (2007) On the origin and evolutionary diversification of beetle 'horns'. Proc Natl Acad Sci USA 104:8661-8668

Feder ME, Burggren WW (1992) Environmental physiology of the amphibians. University of Chicago Press, Chicago

Frankino WA, Pfennig DW (2001) Condition-dependent expression of trophic polyphenism: effects of individual size and competitive ability. Evol Ecol Res 3:939-951

Gross MR (1996) Alternative reproductive strategies and tactics: diversity within sexes. Trends Ecol Evol 11:92-98

Harris RN (1987) Density-dependent paedomorphosis in the salamander Notophthalmus viridescens dorsalis. Ecology 68:705-712

Harris RN, Semlitsch RD, Wilbur HM, Fauth JE (1990) Local variation in the genetic basis of paedomorphosis in the salamander Ambystoma talpoideum. Evolution 44:1588-1603

Hazel WN, Smock R, Johnson MD (1990) A polygenic model for the evolution and maintenance of conditional strategies. Proc R Soc Lond B 242:181-187

Hazel W, Smock R, Lively CM (2004) The ecological genetics of conditional strategies. Am Nat 163:888-900

Johnson E, Whiteman HH, Bierzchudek P (2003) Potential of prey size and type to affect foraging asymmetries in tiger salamanderlarvae (Ambystoma tigrinum nebulosum). Can J Zool 81:17261735

Kikuyama S, Yamamoto K, Kobayashi T, Tonon MC, Galas L, Vaudry $\mathrm{H}$ (2005) Hormonal regulation of growth in amphibians. In Heatwole H (ed) Amphibian biology, endocrinology, vol 6. Surrey Beatty, Chipping Norton, pp 2267-2300

Maret TJ, Collins JP (1997) Ecological origin of morphological diversity: a study of alternative trophic phenotypes in larval salamanders. Evolution 51:898-905

McPeek MA, Holt RD (1992) The evolution of dispersal in spatially and temporally varying environments. Am Nat 140:1010-1027

Nussey DH, Wilson AJ, Brommer JE (2007) The evolutionary ecology of phenotypic plasticity in wild populations. J Evol Biol 20:831-844

Persson L, Byström P, Wahlström E (2000) Cannibalism and competition in Eurasian perch: population dynamics of an ontogenetic omnivore. Ecology 81:1058-1071

Persson L, Claessen D, de Roos AM, Byström P, Sjögren S, Svanbäck R, Westman E (2004) Cannibalism in a size-structured population: energy extraction and control. Ecol Monogr 74:135-157

Pfennig DW (1992) Polyphenism in spadefoot toad tadpoles as a locally-adjusted evolutionarily stable strategy. Evolution 46:14081420

Pfennig DW, McGee M (2010) Resource polyphenism increases species richness: a test of the hypotheses. Phil Trans R Soc Lond B 365:577-591

Pfennig DW, Rice AM, Martin RA (2007) Field and experimental evidence for competition's role in phenotypic divergence. Evolution 61:257-271

Pfennig DW, Wund MA, Snell-Rood EC, Cruickshank T, Schlichting C, Moczek AP (2010) Phenotypic plasticity's impacts on diversification and speciation. Trends Ecol Evol 25:459-467

Pollock KH, Nichols JD, Brownie C, Hines JE (1990) Statistical inference for capture-recapture experiments. Wildl Monogr 107:1-

Relyea RA (2002) Costs of phenotypic plasticity. Am Nat 159:272282

Roff DA (1986) The evolution of wing dimorphisms in insects. Evolution 40:1009-1020

Roff DA (1994) Why is there so much genetic variation for wing dimorphism? Res Popul Ecol 36:145-150

Roff DA (1996) The evolution of threshold traits in animals. Q RevBiol 71:3-35

Roff DA, Fairbairn DJ (1993) The evolution of alternative morphologies: fitness and wing morphology in male sand crickets. Evolution 47:1572-1584

Roff DA, Mostowy S, Fairbairn DJ (2002) The evolution of tradeoffs: testing predictions on response to selection and environmentalvariation. Evolution 56:84-95

Roff DA, Crnokrak P, Fairbairn DJ (2003) The evolution of tradeoffs: geographic variation in call duration and flight ability in the sand cricket, Gryllus firmus. J Evol Biol 16:744-753

Scheiner SM (1993) Genetics and evolution of phenotypic plasticity. Annu Rev Ecol Syst 24:35-68

Schlichting CD (1986) The evolution of phenotypic plasticity in plants. Annu Rev Ecol Syst 17:667-693
Schlichting CD, Pigliucci M (1998) Phenotypic evolution: a reaction norm perspective. Sinauer Associates, Sunderland

Semlitsch RD (1985) Reproductive strategy of a facultatively paedomorphic salamander Ambystoma talpoideum. Oecologia 65:305313

Sexton OJ, Bizer JR (1978) Life history patterns of Ambystoma tigrinum in montane Colorado. Am Midl Nat 99:101-118

Smith CK (1990) Effects of variation in body size on intraspecific competition among larval salamanders. Ecology 71:1777-1788

Smith-Gill SJ (1983) Developmental plasticity: developmental conversion versus phenotypic modulation. Am Zool 23:47-55

Stearns SC (1992) The evolution of life histories. Oxford University Press, New York

Stiffler DF (2005) Endocrine control of water and electrolyte balance in amphibians. In: Heatwole $\mathrm{H}$ (ed) Amphibian biology, endocrinology, vol 6. Surrey Beatty, Chipping Norton, Australia, pp 2301-2326

Thompson JD (1991) Phenotypic plasticity as a component of evolutionary change. Trends Ecol Evol 6:246-249

Tomkins JL, Hazel W (2007) The status of the conditional evolutionarily stable strategy. Trends Ecol Evol 22:522-528

Trivers RL (1972) Parental investment and sexual selection. In: Campbell B (ed) Sexual selection and the descent of man. Aldine, Chicago, pp 136-179

Van Buskirk J, Smith DC (1991) Density-dependent population regulation in a salamander. Ecology 72:1747-1756

Via S (2001) Sympatric speciation in animals: the ugly duckling grows up. Trends Ecol Evol 16:381-390

Via S, Gromulkiewicz R, de Jong G, Scheiner SM, Schlichting CD, Van Tienderen PH (1995) Adaptive phenotypic plasticity: consensus and controversy. Trends Ecol Evol 10:212-217

Wakano JY, Whiteman HH (2008) Evolution of polyphenism: the role of density and relative body size in morph determination. Evol Ecol Res 10:1157-1172

Werner EE, Gilliam JF (1984) The ontogenetic niche and species interactions in size- structured populations. Annu Rev Ecol Syst 15:393-425

West-Eberhard MJ (1986) Alternative adaptations, speciation, and phylogeny (a review). Proc Natl Acad Sci USA 83:1388-1392

West-Eberhard MJ (1989) Phenotypic plasticity and the evolution of diversity. Annu Rev Ecol Syst 20:249-278

West-Eberhard MJ (2003) Developmental plasticity and evolution. Oxford University Press, New York

West-Eberhard MJ (2005) Developmental plasticity and the origin of species differences. Proc Nat Acad Sci USA 102:6543-6549

Whiteman HH (1994) Evolution of facultative paedomorphosis in salamanders. Q Rev Biol 69:205-221

Whiteman HH (1997) Maintenance of polymorphism promoted by sex-specific fitness payoffs. Evolution 51:2039-2044

Whiteman HH, Semlitsch RD (2005) Asymmetric reproductive isolation among polymorphic salamanders. Biol J Linn Soc 86:265281

Whiteman HH, Wissinger SA (2005) Amphibian population cycles and long-term data sets. In: Lannoo ML (ed) Amphibian declines: the conservation status of United States species. University of California Press, Berkeley, pp 177-184

Whiteman HH, Wissinger SA, Bohonak AJ (1995) Seasonal movement patterns in a subalpine population of the tiger salamander Ambystoma tigrinum nebulosum. Can J Zool 72:1780-1787

Whiteman HH, Wissinger SA, Brown WS (1996) Growth and foraging consequences of facultative paedomorphosis in the tiger salamander, Ambystoma tigrinum nebulosum. Evol Ecol 10:433446

Whiteman HH, Sheen JP, Johnson E, VanDeusen A, Cargille RT, Sacco T (2003) Heterospecific prey and trophic polyphenism in larval tiger salamanders. Copeia 2003:56-67

Whiteman HH, Krenz JD, Semlitsch RD (2006) Intermorph breeding and the potential for reproductive isolation in polymorphic mole salamanders (Ambystoma talpoideum). Behav Ecol Sociobiol 60:52-61

Winne CT, Ryan TJ (2001) Aspects of sex-specific differences in the expression of an alternative life cycle in the salamander Ambystoma talpoideum. Copeia 2001:143-149

Wilbur HM (1980) Complex life cycles. Annu Rev Ecol Syst 11:6793

Wilbur HM, Collins JP (1973) Ecological aspects of amphibian metamorphosis. Science 182:1305-1314 
Wissinger SA (1989) Seasonal variation in the intensity of competition and intraguild predation among dragonfly larvae. Ecology 70:1017-1027

Wissinger SA, Whiteman HH (1992) Fluctuation in a Rocky Mountain population of salamanders: anthropogenic acidification or natural variation? J Herpetol 26:377-391

Wissinger SA, Bohonak AJ, Whiteman HH, Brown WS (1999) Subalpine wetlands in Colorado: habitat permanence, salamander predation and invertebrate communities. In: Bazter DP, Wissinger SA (eds) Invertebrates in freshwater wetlands of North America: ecology and management. Wiley, New York, pp 757-790

Wissinger SA, Whiteman HH, Denoël M, Mumford ML, Aubee CB (2010) Consumptive and non-consumptive effects of cannibalism in fluctuating age-structured populations. Ecology 91:549559

\section{Communicated by Ross Alford}

Received: 4 October 2010 / Accepted: 1 July 2011

Published online: 28 July 2011 